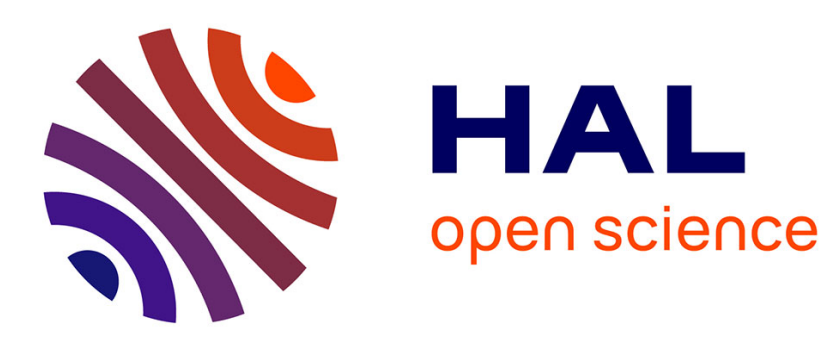

\title{
DIFFUSION OF LITHIUM IONS IN PURE AND DOPED fcc LITHIUM SULFATE
}

\author{
A. Bengtzelius, A. Kvist, A. Lundén
}

\section{To cite this version:}

A. Bengtzelius, A. Kvist, A. Lundén. DIFFUSION OF LITHIUM IONS IN PURE AND DOPED fcc LITHIUM SULFATE. Journal de Physique Colloques, 1973, 34 (C9), pp.C9-199-C9-203. 10.1051/jphyscol:1973937 . jpa-00215412

\section{HAL Id: jpa-00215412 https://hal.science/jpa-00215412}

Submitted on 1 Jan 1973

HAL is a multi-disciplinary open access archive for the deposit and dissemination of scientific research documents, whether they are published or not. The documents may come from teaching and research institutions in France or abroad, or from public or private research centers.
L'archive ouverte pluridisciplinaire HAL, est destinée au dépôt et à la diffusion de documents scientifiques de niveau recherche, publiés ou non, émanant des établissements d'enseignement et de recherche français ou étrangers, des laboratoires publics ou privés. 


\title{
DIFFUSION OF LITHIUM IONS IN PURE AND DOPED fcc LITHIUM SULFATE
}

\author{
A. BENGTZELIUS, A. KVIST and A. LUNDÉN \\ Department of Physics, Chalmers Institute of Technology, \\ S-402 20 Gothenburg 5, Sweden
}

\begin{abstract}
Résumé. - L influence de la concentration sur la diffusion des jons lithium a été étudiée à $620^{\circ} \mathrm{C}$ dans $\mathrm{Li}_{2} \mathrm{SO}_{4} \mathrm{cfc}$ dopé par $\mathrm{MgSO}_{4}$ ( jusqu ia 60 " en fraction molaire) ou par LiCl (jusqu'à $13 \%$ ). Le coefficient de diffusion $D_{1 . i}$ diminue lorsquon ajoute $\mathrm{MgSO}_{4}$, ce qui est logique si les ions lithium occupent des sites octaédriques, landis que les cations en positions tétraédriques doivent être considérés comme des interstitiels. A partir de la croissance de $D_{1, i}$ avec l'addition de $\mathrm{LiCl}$, l'énergie libre de transfert du Li d’une position octaédrique à une position interstitielle est estimée à $0,37 \mathrm{eV}$. Des calculs préliminatires sur ordinateur des potentiels ioniques tendent à confirmer ces résultats expérimentatux.

A partir de mesures antéricures de leffel isolopique, on conclut que le lacteur $\Delta K$ est voisin de l'unité pour la migration de $\mathrm{Li}$ ou $\mathrm{N}$ i dans $\mathrm{Li}_{2} \mathrm{SO}_{4}$. cfe. ce qui signifie que les cations ne partagent pas beaucoup d’énergie avec le réseau des anions lors de leur mouvement. En comparant les données d’autodiffusion el de conductivité. il est conclu à la présence d"une certaine contribution "ring mechanism» sajoutaut au mécanisme lacunaire pour lat migration des ions lithium.

Abstract. - The concentration dependence of the diffusion of lithium ions has been studied at 620 "C in foc $\mathrm{Li}_{2} \mathrm{SO}$, doped with $\mathrm{MgSO}_{4}$ (up 606 mole ") or with LiCl (up 1018 mole $\%$ ). The diffusion coefficient $D_{1 .}$ decreases when $\mathrm{MgSO}_{4}$ is added. which should be expected if the lithium ions occupy octahedral lattice positions, while cations in tetrahedral positions are to be considered as interstitials. From the increase of $\mathrm{D}_{1 . i}$ when $\mathrm{LiCl}$ is added. the Gibbs free energy required to take a $\mathrm{Li}$ ion from an octahedral to an interstitial position is estimated to be $0.37 \mathrm{eV}$. Preliminary computer calculations of ion potentials tend to support these experimental results.

From some previous experiments on isotone eflects it is concluded that the so called $\Delta K$-factor is close to unity for the migration of Li or Na ions in foc $\mathrm{Li}_{2} \mathrm{SO}_{4}$, which means that diffusing cations do not share much energy with the anion latlice. From a comparison between self-diffusion and conductivity data it is concluded that there is a certain contribution from ring mechanisms in addition to the dominating valcancy mechanism for the migration of Li ions.
\end{abstract}

1. Introduction. - The high-lemperalure modification of lithium sulfate, stable in the lemperature range $572-860$ "C $\mathrm{C}$ is characterized by at high cation mobility. The sulfate ions are arranged in a cubic (fcc) or pseudocubic lattice [1], in which octahedra! and tetrahedral positions are available for the ciltions. A number of transporl studies haic been performed in pure $\mathrm{Li}_{2} \mathrm{SO}_{4}$ as well as in the systems where this salt is one of the constituents. Thus dithusion studies in fac $\mathrm{Li}_{2} \mathrm{SO}_{4}$ involve mono- [2]-[4]. di- [5] and trivalent cations [6] as well als some anions [7], and the diffusion coeflicionts are lound to depend on the charge as well as the radius of the diffusing ion. The fairly rapid migration of also rather large anions and cations through the lattice is a consequence of the coupled rotation or strong rotational oscillation that the sulfate ions are performing [1]. and which we have compared with a sistem of cog-wheels [7]. For a model of this lype one might yuestion whether it still is reason to talk of distinct jumps [7]. Whike on the other hand our study of the inorope eflece of thermomigration supports at simple hole model for Li ion transport in fice $\left.I_{1} i_{2} S O\right)_{2}$. in comtrist w the more collective motion in a liquid [8]. However, whatever model that is preferred for the cation transport, there exists different types of cation positions, and the question is which of these that are preferently occupicd by the cations. and which that are racant most of the time. It should be remembered that for geometrical reasons a cation cannot jump directly between two positions of the same type, and that thus either the octahedral or the tetahedral positions should serve as intermediate sites for a migrating cation. In order to get information on site preferences, we decided to study the diffusion of $\mathrm{Li}$ ions in lattices where the number of vacant cation positions is varied by doping with either a divalent cation ( $\mathrm{Mg}$ ) or a monovalent anion (C). In addition some computer calculations are made on a simplified model in order to estimate the energetically most farcurable positions.

2. Experimental. There is a considerable soluhility of $\mathrm{MgSO}_{4}$ as well as of $\mathrm{LCl}$ in foc $\mathrm{Li}_{2} \mathrm{SO}_{4}$ : the phase diagrams of these binary systems have been studied recently in this lahoraltory [9]. [10]. B! using 
the technique described previously [3] a thin layer of lithium sulfate enriched with ${ }^{6} \mathrm{Li}_{2} \mathrm{SO}_{4}$ (from Oak Ridge National Laboratory) was deposited on top of an about $70 \mathrm{~mm}$ high column of salt of the described composition. After an annealing time of about $4 \mathrm{~h}$ at $620^{\circ} \mathrm{C}$, the column was cooled rapidly, and samples taken from the column were analysed with a mass spectrometer in order to determine the isotope abundance ratio ${ }^{7} \mathrm{Li} /{ }^{6} \mathrm{Li}$ as a function of the position. (A more detailed account for experimental details as well as a discussion of possible sources of error is given elsewhere [11].) The calculated diffusion coefficients are listed in tables $I$ and $I I$, and the concentration dependences are shown in figures 1 and 2 .

TABLE I

Diffusion of $\mathrm{Li}^{+}$ions in $\left(\mathrm{Li}_{2}, \mathrm{Mg}\right) \mathrm{SO}_{4}$ at $620{ }^{\circ} \mathrm{C}$

$\begin{array}{ccc}\begin{array}{c}x \\ \text { mole }\end{array} \mathrm{MgSO}_{4} & \begin{array}{c}D \times 10^{5} \\ \mathrm{~cm}^{2} / \mathrm{s}\end{array} & \begin{array}{c}\text { Time } \\ \text { min }\end{array} \\ - & - & - \\ 0 & 1.90 & 244 \\ 10 & 1.57 & 238 \\ 20 & 1.50 & 240 \\ 35 & 1.23 & 233 \\ 40 & 1.10 & 235 \\ 50 & 0.72 & 960 \\ 60 & 0.60 & 200\end{array}$

TABLE II

Diffusion of $\mathrm{Li}^{+}$ions at $620{ }^{\circ} \mathrm{C}$ in $\mathrm{fcc} \mathrm{Li}_{2} \mathrm{SO}_{4}$ doped with $\mathrm{LiCl}$

\begin{tabular}{ccc}
$\begin{array}{l}y \\
\text { mole }\end{array}$ & $\begin{array}{c}D \times 10^{5} \\
\mathrm{~cm}^{2} / \mathrm{s}\end{array}$ & $\begin{array}{c}\text { Time } \\
\text { min }\end{array}$ \\
\hline- & - & - \\
0 & 1.90 & 244 \\
4.9 & 2.17 & 260 \\
9.2 & 2.73 & 253 \\
14.0 & 3.32 & 240 \\
18.2 & 3.61 & 248
\end{tabular}

3. Computer calculations. - Flygare and Huggins [12] have recently presented calculations on the transport of ions through crystallographic tunnels in solid electrolytes. We decided to test for a simple model whether tetrahedral or octahedral cation positions are energetically most favourable. We consider the sulfate ions as spheres forming an fcc lattice. The interaction between an arbitrary cation $\mathbf{M}^{\mathbf{z}}$ (either $\mathrm{Li}^{+}$or an impurity cation) and all other ions is studied. The $\mathrm{M}^{\mathrm{z}+}-\mathrm{SO}_{+}^{2-}$ interaction is assumed to consist of Coulomb attraction and overlap repulsion, while only Coulomb repulsion is considered for the $\mathrm{M}^{2+}-\mathrm{Li}^{+}$interaction. The overlap repulsion is expressed by a function of the form $B /\left(\mathbf{r}_{\mathrm{i}}-\mathbf{r}\right)^{n}$, where $\mathbf{r}_{\mathbf{i}}$ is the vector of the $\mathrm{SO}_{4}^{2-}$ ion, $\mathbf{r}$ the vector of the $\mathrm{M}^{\mathrm{z}+}$ ion, $n$ an integer parameter and $B$ a constant. When calculating the total energy of the mobile cation $\mathrm{M}^{z^{+}}$, all coulombic contributions are included, but for the overlap repulsion only nearest neighbours are considered. A more detailed account of the chosen method and of the results of the calculations is given elsewhere [11]. The choice of the parameters $r_{0}$, i. e. the equilibrium distance for the system $\mathrm{M}^{2+}-\mathrm{SO}_{4}^{2-}$, and $n$ becomes more complicated for a polyatomic anion like $\mathrm{SO}_{4}^{2-}$ than for monoatomic ions, since the cations can easily penetrate into the "valleys» between the interpenetrating oxygen atoms. The combination of a large $r_{0}$ and low $n$ corresponds to a "soft " sulfate ion, while a small $r_{0}$ and a large $n$ would represent the "hard core" of the sulfate ion. In a discussion of the structure of molten sulfates Zarzycki [13] considers $1.94 \AA$ as the shortest possible Li-S distance, but finds from free volume calculations that the average distance is likely to be somewhere between 2.5 and $3.5 \AA$, i. e. not so far from the average of $3.3 \AA$ interpreted from the $X$-ray study of fcc $\mathrm{Li}_{2} \mathrm{SO}_{4}[1]$. In their calculations on transport in Agl Flygare and Huggins [12] used a repulsion radius for the iodine ion which is somewhat smaller than the Pauling radius, and we decided to start with a hard core calculation with $r_{0}=2.0 \AA$ and $n=9$. In this case consistency was obtained for the assumption that each octahedral position is occupied by two Li-ions (the repulsion between the two Li-ions was neglected in this calculation), but not for the alternative that the Li-ions instead are in tetrahedral positions. The next step was to try to calculate the potential barrier a cation has to overcome in order to get from one octahedral position to another. In the calculations done so far, we continued to use short equilibrium distances $\left(r_{0}\right)$ in combination with normal (or high) values of the repulsion parameter $n$. In this way good agreement was obtained [11] between computed and experimental activation energies for diffusion of mono- and divalent cations in fcc $\mathrm{Li}_{2} \mathrm{SO}_{4}$. It remains, however, to make computations also for other values of $r_{0}$, before one can judge the merits of the chosen model. A further refinement suggested by Krogh-Moe [14] would be to displace the sulfate ion slightly from the fixed position that it has in the present computer model.

4. Interpretation of isotope effects. - Information on the transport mechanism can be obtained from isotope effect studies. Two types of isotope eflects have been studied previously in fec $\mathrm{Li}_{2} \mathrm{SO}_{4}$, and it is reason to adjust the interpretation slightly. A study of simultaneous diffusion of ${ }^{22} \mathrm{Na}$ and ${ }^{24} \mathrm{Na}$ gave a relative difference in diffusion coefficients of $\Delta D / D=2.8 \pm 0.4 \%[15]$ and from a comparison of the electrical conductivity of ${ }^{6} \mathrm{Li}_{2} \mathrm{SO}_{4}$ and ${ }^{7} \mathrm{Li}_{2} \mathrm{SO}_{4}$ Schroeder and Kvist [16] obtained

$$
\Delta \kappa / \kappa=4.73 \pm 0.40
$$


Neither isotope effect showed any significant temperature dependence. From these results it follows [17], that

$$
f \Delta K_{\mathrm{Na}}=0.64 \pm 0.09
$$

and

$$
f \Delta K_{\mathrm{Li}}=0.63 \pm 0.05
$$

where $f$ is the correlation factor and $\Delta K$ represents the distribution or sharing of kinetic energy between the migrating ion and the rest of the lattice. Although the excellent agreement between the diffusion and the conductivity experiment might be fortuitous, it supports the assumption that the transport mechanism is the same for $\mathrm{Li}^{+}$and $\mathrm{Na}^{+}$ions in $\mathrm{fcc}_{2} \mathrm{Li}_{2} \mathrm{SO}_{4}$. Since an octahedral position is surrounded by 8 tetrahedral positions while a tetrahedral position has 4 neighbouring octahedral ones, the correlation factor is not the same for the two types of cation jumps that occur in $\mathrm{fcc} \mathrm{Li}_{2} \mathrm{SO}_{4}$. To our knowledge there are no calculations of the correlation factor for a case like this, but since the average number of neighbouring positions is 6 , we expect the correlation factor to be close to that of a simple cubic lattice $(f=0.6555)$, and we then obtain $\Delta K=0.97$, which does not differ significantly from unity. This means that the diffusing cation does not share much energy with the surrounding anions. Our result is in agreement with a recent calculation for $\mathrm{Na}^{+}$diffusion in $\mathrm{NaCl}$, where $\Delta K=0.998$ was obtained [18].

A comparison for pure $\mathrm{Li}_{2} \mathrm{SO}_{4}$ between the selfdiffusion coefficient [2], $D_{\mathrm{T}}$, and conductivity data shows that the ratio $D_{\mathrm{T}} / D_{\mathrm{c}}\left(0.91\right.$ at $600{ }^{\circ} \mathrm{C}: 0.71$ at $800{ }^{\circ} \mathrm{C}$ ) is larger than the assumed correlation factor. This indicates that there is a contribution from a ring mechanism in addition to the vacancy mechanism, with which both $\mathrm{Li}^{+}$and $\mathrm{Na}^{+}$ions diffuse according to the isotope effect studies discussed above.

5. Interpretation of diffusion in doped $\mathrm{Li}_{2} \mathrm{SO}_{4}$. Let us distinguish for fcc $\mathrm{Li}_{2} \mathrm{SO}_{4}$ between two types of cation sites, of which most of the \%-sites are occupied while most of the $\beta$-sites are vacant. Since there is adequate space for two Li-ions in an octahedral position, each such position can be considered as two cation sites, and the number of $\alpha$ - and $\beta$-sites thus becomes equal. The energy required to create a vacancy is estimated to be $0.24 \mathrm{eV}$ [11], and thus we might expect that at 600 " $\mathrm{C}$ some $80 \%$ of the $\alpha$ - and $20 \%$ of the $\beta$-sites are occupied by Li-ions.

The diffusion coefficient is so much less for $\mathrm{Mg}^{2+}$ ions than for $\mathrm{Li}^{+}$ions $\left(D_{\mathrm{Mg}} / D_{\mathrm{Li}}=0.03\right.$ at $620{ }^{\circ} \mathrm{C}$ for nearly pure lithium sulfate [5]) that we can consider the $\mathrm{Mg}^{2+}$ ion as immobile when discussing diffusion in doped $\mathrm{Li}_{2} \mathrm{SO}_{4}$. As shown in figure 1 the diffusion coefficient $D_{t . \mathrm{i}}$ was found 10 decrease approximately linearly when the concentration of $\mathrm{Mg}$ is incrased. An added $\mathrm{Mg}^{2+}$ ion replaces two $\mathrm{Li}^{+}$ions. If these

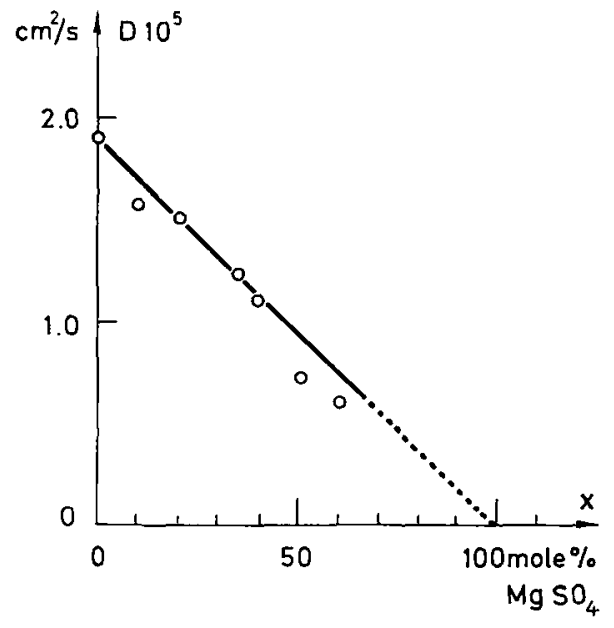

FIG. 1, - Diffusion of $\mathrm{Li}^{+}$ions in $\left(\mathrm{Li}_{2}, \mathrm{Mg}\right) \mathrm{SO}_{4}$ at $620^{\circ} \mathrm{C}$. The straight line is the concentration dependence to be expected if the $\mathrm{Li}$ ions are in octahedral positions, cf. eq. (4).

were occupying tetrahedral positions, the number of vacant tetrahedral positions would increase when $\mathrm{Mg}^{2+}$ is added, and we should expect an increase in $D_{\mathrm{L}, \mathrm{i}}$, but if, on the other hand two $\mathrm{Li}^{+}$ions in an octahedral position are replaced by a $\mathrm{Mg}^{2+}$, there will be no change in the number of vacant sites, and due to the increased blocking of tetrahedral sites (see below), $D_{\mathrm{Li}}$ should decrease when the mole fraction of $\mathrm{MgSO}_{4}(x)$ is increased. Thus we arrive at the conclusion that the $y$-sites correspond to octahedral positions, and the tetrahedral positions to interstitial ones, some of which are occupied by activated cations. The system can be treated in analogy with a crystal with Frenkel defects.

Consider a system where we per unit volume have $N$ lattice sites, ( $\frac{1}{2} N$ octahedral positions), $n_{v}$ vacant lattice sites, $N_{\mathrm{L} . \mathrm{i}}$ lithium ions and $N_{\mathrm{i}}$ interstitial positions ( $=$ the number of tetrahedral positions times an availability factor; see below). The mole fraction of $\mathrm{MgSO}_{4}$ is $x$. Consider migration by a vacancy mechanism for which

$G_{\mathrm{m}}=$ Gibbs free energy of activation [19]; free energy barrier that opposes the migration [20];

$G_{\mathrm{f}}=$ energy required to take a $\mathrm{Li}$ ion from an octahedral to an interstitial position $\left(2 G_{f}\right.$ required to take an $\mathrm{Mg}$ ion to an interstitial position; the $\mathrm{Li}^{+}$and $\mathrm{Mg}^{2+}$ ions have approximately the same radius) :

$r$ = vibration frequency (of an ion in the potential minimum) :

$a=$ the jump distance.

We have (a more detailed discussion is given elsewhere [11])

$$
n_{\mathrm{s}}=\left(N_{\mathrm{Li}} N_{\mathrm{i}}\right)^{1 / 2} \exp \left(-\frac{1}{2} G_{\mathrm{f}} / k T\right)
$$

where $N_{1, i}=(1-x) N$.

The availability of an interstitial position depends on the concentration of $\mathrm{Mg}^{2+}$ ions. If immobile 
$\mathrm{Mg}$ ions surround all tetrahedral positions $(x=1)$, none of these would be available, and $N_{\mathrm{i}}(1)=0$, while if $x=0$, we have $N_{\mathrm{i}}(0)=N$. Let us assume that $N_{\mathrm{i}}$ is a linear function of $x$

$$
N_{\mathrm{i}}=(1-x) N \text {. }
$$

The diffusion coefficient for $\mathrm{Li}$ ions in $\left(\mathrm{Li}_{2}, \mathrm{Mg}\right) \mathrm{SO}_{4}$ becomes

$$
D=\frac{1}{6} f a^{2} v(1-x) \exp \left(-\left[\frac{1}{2} G_{\mathrm{f}}+G_{\mathrm{m}}\right] / k T\right)
$$

or

$$
D=(1-x) D_{0} \exp (-Q / k T)
$$

where

$$
D_{0}=\frac{1}{6} f a^{2} v \exp \left(\left[\frac{1}{2} S_{\mathrm{f}}+S_{\mathrm{m}}\right] / k T\right)
$$

and

$$
Q=\frac{1}{2} H_{\mathrm{f}}+H_{\mathrm{m}}
$$

( $S$ denotes entropy and $H$ enthalpy terms).

$D_{\mathrm{Li}}$ increases when $\mathrm{LiCl}$ is added to $\mathrm{Li}_{2} \mathrm{SO}_{4}$, see figure 2 , because a vacancy is introduced in the cation substructure, when an $\mathrm{SO}_{4}^{2-}$ is replaced by a $\mathrm{Cl}^{-}$ion.

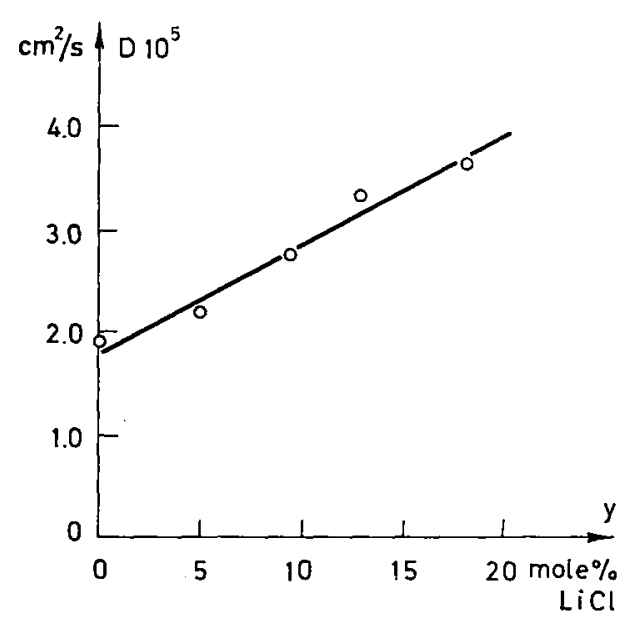

Fig. 2. - Diffusion of $\mathrm{Li}^{+}$ions at $620{ }^{\circ} \mathrm{C}$ in fcc $\mathrm{Li}_{2} \mathrm{SO}_{4}$ doped with $\mathrm{LiCl}$. The straight line corresponds to eq. (9).

Thus

$$
\begin{aligned}
n_{\mathrm{v}}= & \left(N_{\mathrm{Li}} N_{\mathrm{i}}\right)^{1 / 2} \exp \left(-\frac{1}{2} G_{\mathrm{f}} / k T\right)+N_{\mathrm{C} 1}= \\
= & {\left[N\left(1-\frac{1}{2} y\right) N_{\mathrm{i}}\right]^{1 / 2} \exp \left(-\frac{1}{2} G_{\mathrm{f}} / k T\right)+\frac{1}{2} N y }
\end{aligned}
$$

where $N_{\mathrm{Cl}}$ is the number of $\mathrm{Cl}$ ions per unit volume, and $y$ is the mole fraction of $\mathrm{LiCl}$. With the approximation $\left[N\left(1-\frac{1}{2} y\right) N_{\mathrm{i}}\right]^{1 / 2} \simeq N$, we obtain the diffusion coefficient for $\mathrm{Li}$ ions in $\mathrm{Li}_{2}\left(\mathrm{SO}_{4}, \mathrm{Cl}_{2}\right)$

$D=\frac{1}{6} f a^{2} v \exp \left(-G_{\mathrm{m}} / k T\right)\left[\exp \left(-\frac{1}{2} G_{\mathrm{f}} / k T\right)+\frac{1}{2} y\right]$ or

$$
D=A+B y
$$

Thus

$$
G_{\mathrm{f}}=2 k T \ln (2 B / A) \text {. }
$$

From the experimental data we obtain $A=1.813 \times 10^{-5} \mathrm{~cm}^{2} / \mathrm{s}, B=10.28 \times 10^{-5} \mathrm{~cm}^{2} / \mathrm{s}$ and $G_{\mathrm{f}}=0.37 \mathrm{eV}$.

The activation energy for cation self-diffusion in pure $\mathrm{Li}_{2} \mathrm{SO}_{4}$ is $Q=0.34 \mathrm{eV}$ [2], and if we approximate $H_{\mathrm{f}}=G_{\mathrm{f}}$, it follows from eq. (6) that $H_{\mathrm{m}}=0.15 \mathrm{eV}$. This experimental result can be compared with computed values of the potential barrier for migration of $\mathrm{Li}$ ions. So far we have made a computation only for the combination $r_{0}=1.91 \AA$ and $n=7$, which gave $H_{\mathrm{m}}=0.24 \mathrm{eV}$ [11]. The agreement between the two values of $H_{\mathrm{m}}$ is satisfactory, if one considers the approximations involved in the simple model used for the computations and in the interpretation of the experiments. E. g. when calculating $G_{\mathrm{f}}$ by means of eq. (10), we have assumed that the observed increase in $D_{L, i}$ with increasing $!$ is due only to an increase in the number of vacant cation sites. We know, however, that $D_{\mathrm{Cl}}$ increases too when $\mathrm{LiCl}$ is added [7], and there is reason to believe that deformation of the anion lattice and changes of the rotational properties of the sulfate ions has some influence also on $D_{\mathrm{L} . \mathrm{i}}$. If one should assume that, say, $20 \%$ of the coefficient $B$ in eq. (9) had other causes than the increase in the number of vacancies, this would change $G_{\mathrm{f}}$ to $0.34 \mathrm{eV}$ and $H_{\mathrm{m}}$ to $0.18 \mathrm{eV}$. When deriving eq. (8) we have assumed that $G_{\mathrm{m}}$ and $G_{\mathrm{r}}$ are independent of the composition of the mixture. This has not been checked experimentally for diffusion, but it is known that the activation energy of conductivity is approximately the same in the whole concentration range [7].

6. General conclusions. - If, in addition to the diffusion studies and computer calculations (which so far are to be regarded as preliminary), one also considers investigations of conductivity, electromigration and thermomigration in $\mathrm{Li}_{2} \mathrm{SO}_{4}$-rich $\mathrm{fec}$ phases, one finds that difficult problems remain to be solved concerning the migration of large cations, such as potassium [21], but it is also evident that all the results seem to be consistent with a model where the lithium ions normally occupy octahedral positions, and where the transport of at least lithium and sodium ions predominantly takes place by a vacancy mechanism with a certain contribution from some kind of ring mechanism.

7. Acknowledgments. - This investigation is supported by the Swedish Board of Technical Development and by the Swedish Natural Science Research Council. Our thanks are due to $\mathrm{Mr}$. M. Lövenby for performing the mass analyses. 


\section{References}

[1] Forland, T. and Krogh-Moe, J., Acta Chem. Scand. 11 (1957) 565.

[2] Kvist, A. and Trolle, U., Z. Naturforsch. 22a (1967) 213.

[3] Kvist, A. and Bengtzelius, A., Z. Naturforsch. 23a (1968) 679.

[4] Inman, D. and Johnson, M., J. Appl. Electrochem. 2 (1972) 347.

[5] Kvist, A., Bengtzelius, A. and Trolle, U., Z. Naturforsch. 23a (1968) 2042 .

[6] Bengtzelius, A., Josefson, A.-M., Kvist, A. and SchroeDER, K., Z. Naturforsch. 25a (1970) 1921.

[7] Kvist, A. and Bengtzelius, A., Fast lon Transport in Solids, ed. van Gool, W. (North-Holland Publ. Co., Amsterdam) 1973, p. 193.

[8] Lundén, A., Atomic Transport in Solids and Liquids, ed. Lodding, A. and Lagerwall, T. (Verl. Z. Naturforsch., Tübingen) 1971, p. 302.

[9] Tärneberg, R., Ljungmark, H., Kvist, A. and BengtzeLIUS, A., unpublished.
[10] LJUNGMARK, H. and Kvist, A., unpublished.

[11] Bengtzelius, A., Thesis, University of Gothenburg 1973.

[12] Flygare, W. H. and Huggins, R. A., J. Phys. Chem. Solids 34 (1973) 1199

[13] Zarzyckı, J., Disc. Furaday Soc. 32 (1961) 38.

[14] Krogh-Moe, J., Priv. Com.

[15] Bengtzelius, A. and Kvist, A., Z. Naturforsch. 24a (1969) 468.

[16] Schroeder, K. and Kvist, A., Z. Naturforsch. 25a (1970) 1365.

[17] Le Claire, A. D., Phil. Mag. 14 (1966) 1271.

[18] Brown, R. C., Worster, J., March, N. H., Perrin, R. C. and Bullough, R., Phil. Mag. 23 (1971) 555.

[19] Lidiard, A. B., Handbuch der Physik 20246 (SpringerVerlag, Berlin) 1957.

[20] Bénière, F., Physics of Electrolytes, Vol. 1, p. 203, éd. Hladik, J. (Academic Press, London) 1972.

[21] Lundén, A., Floberg, M. and Mattsson, R., Z. Naturforsch., in the press. 